\title{
Human Functioning: Developments and Grand Challenges
}

\author{
Jerome Bickenbach ${ }^{1,2 *}$ \\ ${ }^{1}$ Swiss Paraplegic Research, Nottwil, Switzerland, ${ }^{2}$ Department of Health Sciences and Medicine, University of Lucerne, \\ Lucerne, Switzerland
}

Keywords: functioning, challenge, epidemiology, clinical practice, research, International Classification of Functioning, Disability and Health

\section{ICF AND FUNCTIONING: THE PARADIGM SHIFT}

Like many ground-breaking innovations, the conceptual thinking that went into The World Health Organization's International Classification of Functioning, Disability and Health (ICF) in the early 1990s had been anticipated in the literature for decades, although formally endorsed by the WHO in 2001, the result was a true paradigm shift (1). With the ICF, WHO made it clear that, although health states are purely biological phenomena, what matters to people about their health is not merely these biological processes but also the concrete impact on their daily lives: what they can do and be, the actions they perform and the life goals and aspirations they can achieve. The ICF made it clear that challenges to our health-disease, injuries, and the natural process of aging itself-bring about decrements in body functions and alterations of body structure, and these changes, in interaction with the environment, can negatively affect-sometimes trivially, sometimes profoundly - what we can do and achieve in our lives.

To capture this multifaceted and continuous phenomena, the ICF proposes the term functioning - the sum total of functions and structures of the body and mind, the actions people perform, and the complex and socially-embed life activities they participate in. Functioning, as a term of science, requires both a conceptual description or model and, for scientific description, operationalization and measurement, a classification of the lived experience of health. The ICF provided both. The notion of functioning has in the last 20 years made it possible to clarify the concept and practice of healthcare, and most particular the concept and practice of rehabilitation. The ICF notion of functioning provides a clearer understanding of the health and social impact of future trends in population aging and increased prevalence of non-communicable diseases, trends that will reveal the increasing need for, and social value of rehabilitation as a health strategy.

Since 2001, the ICF has been widely and diversely applied as a standard classification, an international reference language for the collection of information about the lived experience of health. The ICF complements and supplements the WHO's International Classification of Diseases (ICD) (2) as well as, more recently, the International Classification of Health Intervention (ICHI) (3). WHO's primary purpose in promulgating each of these standards is to ensure comparability of international health information-information that is of practical use to practitioners and researchers to explain and influence functioning both clinically and at the population level, and to policy-makers striving to improve the performance of national health systems to respond to the functioning needs of individuals and populations. The future of e-health and all digital applications of health information depends on data standardization, as does a more comprehensive epidemiology that goes beyond the standard health indicators of mortality and morbidity.

The conceptual foundations of the ICF notion of human functioning has also spurred research and applications that have had a fundamental and diverse impact on health sciences and health and social policy. Functioning is conceptualizes in the ICF in terms of a person-environment interaction, which in turn has led to the important conceptual distinction between a person's intrinsic health capacity and the person's actual, real world performance in which her or 
his physical, human-built, attitudinal, and socio-political environment may hinder or enhance performance. This model has been particularly useful in clarifying the notion of disability as a problem, decline, or non-optimal functioning in one or more domains. This understanding of disability has lead to a rethinking of the most prominent policy applications of the notion of disability, and in particularly that of disability assessment and determination processes for health and social benefits, including the need for vocational rehabilitation. Rather than understanding disability purely from the perspective of biomedical phenomena, the ICF has underwritten the more robust and valid notion of disability as the outcome of an interaction between intrinsic health capacity, personal factors, and the environment.

The last two decades of research and application of the ICF and its key notion of functioning point to an active future of grand challenges for rehabilitation.

\section{CLARIFICATION OF THE AIM AND SCOPE OF REHABILITATION AS A HEALTH STRATEGY}

As one of the five health strategies recognized by the WHO, rehabilitation has historically been undervalued and misunderstood, in part because, unlike curative medicine and health promotion and disease prevention, rehabilitation seemed to have a somewhat vague aim and purely reactive posture. Recent work on the conceptualization of rehabilitation (4-7), however, has argued that the notion of functioning may be the key to a new understanding in which the aim of rehabilitation is to optimize functioning in the face of demographic and epidemiological trends that point to a future of increased population disability. It remains a challenge how this insight can be used to further clarify the role and purpose of rehabilitation as a fundamental health strategy. Equally challenging is to ensure that rehabilitation is not merely a high-income country health strategy but its aim and scope can be effectively implemented in low- and middle-income countries as well.

\section{REHABILITATION ASSESSMENT AND EVALUATION USING FUNCTIONING}

In practical terms, clinicians require tools and an operational language in which to assess their patients and evaluate the quality and effectiveness of rehabilitation interventions. Given the importance of this area of clinical practice, there is a growing literature on the use of ICF and functioning in the development of clinical assessment, evaluation and quality management tools and methodologies (8-11). The challenge in the future is to both to continue this development, and as far as possible, to ensure comparability between approaches to rehabilitation assessment and evaluation, and recognition of the importance of rehabilitation across health and social sectors.

\section{FUNCTIONING AND REHABILITATION GOAL-SETTING AND OUTCOME MEASURES AND TOOLS}

The other major component of intervention planning for rehabilitation is goal-setting that is patient-oriented (12-14) as well as the development and application of clinical (15-17) and patient-reported $(18,19)$ outcome measures and related tools that reflect these goals. There is perhaps nothing more important to rehabilitation as a clinical practice than that practitioners are able to set goals and identify outcomes that represents what is of importance to the beneficiary of rehabilitation interventions. For this the notion of functioning is ideal as it captures the lived experience of health and so what actually matters to be able their health in the daily lives and over the life course.

\section{ICF AS REFERENCE FRAMEWORK FOR FUNCTIONING INFORMATION}

For functioning to play a role in clinical practice-either in assessment, goal-planning, outcomes, and evaluation-work needs to be done on standardized clinical reporting of the functioning information $(20,21)$. The case needs to be made, to the satisfaction of health policy-makers, that functioning information should be fully integrated into health information systems $(22,23)$, potentially within electronic health records (24). Although the groundwork for using ICF as an international reference framework for functioning information has been laid, the challenge remains to break down the barriers to an increased demand for functioning information from clinical and a recognition on the part of policy makers of the need for routine collection of functioning information in order to strengthening rehabilitation within the health system. A companion challenge is to facilitate the role of functioning information in evidencebased policy development, responsive to the relevance and value of this information, not merely in the health sector, but in the social, labor, and education sectors as well.

\section{ECONOMIC EVALUATION OF REHABILITATION INTERVENTIONS}

One of the challenges identified in the WHO?s call for action Rehabilitation 2030 is to convince countries of the importance of strengthening rehabilitation within national health systems, especially in light of anticipated increased need for rehabilitation given population aging and the increased prevalence of noncommunicable diseases (25). Making this case, at the national level, requires a demonstration that rehabilitation is not an added cost, but an important economic investment. The economic argument, recent work has suggested, can best be made where the economic benefit of rehabilitation is expressed in terms of functioning improvements $(26,27)$, but far more work needs to be done in order to fully make the economic investment argument. 


\section{WORK CAPACITY ASSESSMENT FOR VOCATIONAL REHABILITATION}

Around the globe, countries are realizing that it no longer makes economic or political sense to use pensions and other social policy mechanisms to exclude people experiencing disability from entering and participating in the labor market. With support, even those with severe and long-lasting impairments can be employed: it is a fundamental human rights issue (28). Vocational rehabilitation can open the door to employment and the notion of functioning has been shown to be the key metric for assessment of work capacity $(29,30)$, the need for vocational rehabilitation (31), and job matching (32). It remains a challenge to explore the role of functioning as the basis for return-to-work and other work related social strategies, and developing tools that ensure that people experiencing disability are, and remain, active participants in the labor market.

\section{DEVELOPMENT OF ENVIRONMENTAL MEASUREMENT TOOLS}

At the heart of the ICF concept of functioning is the insight that human functioning is an outcome of complex interactions between a person's intrinsic health capacity, determined by the extent and severity of health conditions that are present, and the physical, human-being, attitudinal, social, and political environment in which the individual lives and carries out her or his life. This constituents ICF's "paradigm shift" in the understanding of the concepts of functioning, disability, and health. Yet, although the health sciences have made considerable progress toward understanding and explaining the kinds of problems and limitations in health capacity that human experience, we are just beginning to develop the science of describing and measuring the impact of the environment on functioning $(33,34)$. Understanding how our environment, in all of its diversity, shapes human functioning remains a challenge for the future.

\section{REFERENCES}

1. World Health Organization. International Classification of Functioning, Disability and Health. (2001). Available online at: https://www.who.int/ classifications/icf/en/ (accessed 12 October, 2020).

2. World Health Organization. International Classification of Diseases, ICD11. (2020). Available online at: https://www.who.int/classifications/icd/en/ (accessed 12 October, 2020).

3. World Health Organization. International Classification of Health Interventions. (2019). Available online at: https://www.who.int/classifications/ ichi/en/ (accessed 12 October, 2020).

4. Stucki G, Melvin J. The International Classification of Functioning, Disability and Health: a unifying model for the conceptual description of physical and rehabilitation medicine. J Rehabil Med. (2007) 39:286-92. doi: 10.2340/16501977-0044

5. Gutenbrunner C, Bickenbach J, Kiekens C, Meyer T, Skempes D, Nugraha $\mathrm{B}$, et al. ISPRM discussion paper: proposing dimensions for an international classification system for service organization in health-related rehabilitation. $J$ Rehabil Med. (2015) 47:809-15. doi: 10.2340/16501977-2002

\section{PROSPECTS OF AN EPIDEMIOLOGY OF FUNCTIONING}

Finally, and in a sense most fundamentally, the notion of functioning has the potential of reorienting the basic health science of epidemiology itself, an epidemiology that includes but moves beyond biomedical epidemiology toward a more comprehensive understanding of health: an epidemiology of functioning in the light of health conditions (35). An epidemiology of functioning would seek to understand the health capacity and environmental determinants of people's actual experience of living with health conditions in their environments. Developing population metrics of functioning (36) and with the availability of very large data sets constructing functioning trajectories of aging (37) should assist in identifying identify epidemiological patterns that would greatly enhance our ability to determine the efficacy of functioning-based intervention along the life-course. As our understanding of functioning improves, and our assessment and measurement instrumentation is perfected, the challenge of a true epidemiological of functioning may be within our reach.

\section{CONCLUSIONS}

The notion of human functioning, grounded in the ICF has in the past two decades led to a growing body of scientific literature in health generally, and rehabilitation in particular. These challenges, and undoubtedly many others that reveal themselves in future years, will raise questions that demand the highest quality scientific investigation and research. The future for research in human functioning is indeed bright.

\section{AUTHOR CONTRIBUTIONS}

The author confirms being the sole contributor of this work and has approved it for publication.

6. Meyer T, Gutenbrunner C, Kiekens C, Skempes D, Melvin JL, Schedler $\mathrm{K}$, et al. ISPRM discussion paper: proposing a conceptual description of health-related rehabilitation services. J Rehabil Med. (2014) 46:1-6. doi: 10.2340/16501977-1251

7. Negrini S, Meyer T, Arienti C, Kiekens C, Pollock A, Selb M, et al. The 3rd cochrane rehabilitation methodology meeting: "rehabilitation definition for scientific research purposes”. Eur J Phys Rehabil Med. (2020) 56:658-60. doi: 10.23736/S1973-9087.20.06574-0

8. Soler B, Ramari C, Valet M, Dalgas U, Feys P. Clinical assessment, management, and rehabilitation of walking impairment in MS: an expert review. Expert Rev Neurother. (2020) 20:875-86. doi: 10.1080/14737175.2020.1801425

9. Postma SAE, van Boven K, Ten Napel H, Gerritsen DL, Assendelft WJJ, Schers $\mathrm{H}$, et al. The development of an ICF-based questionnaire for patients with chronic conditions in primary care. J Clin Epidemiol. (2018) 103:92-100. doi: 10.1016/j.jclinepi.2018.07.005

10. Prodinger B, Scheel-Sailer A, Escorpizo R, Stucki G. European initiative for the application of the International Classification of Functioning, Disability and Health: development of clinical assessment schedules for 
specified rehabilitation services. Eur J Phys Rehabil Med. (2017) 53:319-32. doi: 10.23736/S1973-9087.16.04438-5

11. Prodinger B, Tennant A, Stucki G, Cieza A, Üstün TB. Harmonizing routinely collected health information for strengthening quality management in health systems: requirements and practice. J Health Serv Res Policy. (2016) 21:223-8. doi: $10.1177 / 1355819616636411$

12. Rasová K, Martinková $\mathrm{P}$, Soler B, Freeman J, Cattaneo D, Jonsdottir J, et al. Real-world goal setting and use of outcome measures according to the International Classification of Functioning, Disability and Health: a European survey of physical therapy practice in multiple sclerosis. Int J Environ Res Public Health. (2020) 17:4774. doi: 10.3390/ijerph17134774

13. Angeli JM, Schwab SM, Huijs L, Sheehan A, Harpster K. ICF-inspired goal-setting in developmental rehabilitation: an innovative framework for pediatric therapists. Physiother Theory Pract. (2019) 26:1-10. doi: 10.1080/09593985.2019.1692392

14. Dutzi I, Schwenk M, Kirchner M, Bauer JM, Hauer K. "What would you like to achieve?" Goal-setting in patients with dementia in geriatric rehabilitation. BMC Geriatr. (2019) 19:280. doi: 10.1186/s12877-0191296-7

15. Keen C, Harrop D, Hashmi-Greenwood MN, Kiely DG, Yorke J, Sage $\mathrm{K}$. Outcome measures used in studies of rehabilitation in pulmonary hypertension: a systematic review. Ann Am Thorac Soc. (2020) 18:321-35. doi: 10.1513/AnnalsATS.202005-541OC

16. Patel K, Straudi S, Yee Sien N, Fayed N, Melvin JL, Sivan M. Applying the WHO ICF framework to the outcome measures used in the evaluation of long-term clinical outcomes in coronavirus outbreaks. Int J Environ Res Public Health. (2020) 17:E6476. doi: 10.3390/ijerph17186476

17. van Heugten C, Caldenhove S, Crutsen J, Winkens I. An overview of outcome measures used in neuropsychological rehabilitation research on adults with acquired brain injury. Neuropsychol Rehabil. (2020) 30:1598-623. doi: 10.1080/09602011.2019.1589533

18. Tucker CA, Cieza A, Riley AW, Stucki G, Lai JS, Bedirhan Ustun T, et al. Concept analysis of the patient reported outcomes measurement information system (PROMIS ${ }^{\circledR}$ ) and the International Classification of Functioning, Disability and Health (ICF). Qual Life Res. (2014) 23:1677-86. doi: 10.1007/s11136-014-0622-y

19. Algurén B, Coenen M, Malm D, Fridlund B, Mårtensson J, Årestedt K, et al. A scoping review and mapping exercise comparing the content of patientreported outcome measures (PROMs) across heart disease-specific scales. $J$ Patient Rep Outcomes. (2020) 4:7. doi: 10.1186/s41687-019-0165-7

20. Prodinger B, Stamm T, Peterson D, Stucki G, Tennant A, International Classification of Functioning, Disability, and Health Info Network. Toward a standardized reporting of outcomes in hand osteoarthritis: developing a common metric of outcome measures commonly used to assess functioning. Arthritis Care Res. (2016) 68:1115-27. doi: 10.1002/acr.22816

21. Prodinger B, Tennant A, Stucki G. Standardized reporting of functioning information on ICF-based common metrics. Eur J Phys Rehab Med. (2018) 54:110-7. doi: 10.23736/S1973-9087.17.04784-0

22. Hopfe M, Prodinger B, Bickenbach J, Cieza A, Stucki G. Optimizing existing health systems: an argument for integrating functioning information. $B M C$ Health Ser Res. (2014) 14:56. doi: 10.1080/09638288.2017.1334234

23. Stucki G, Bickenbach J, Melvin J. Strengthening rehabilitation in health systems worldwide by integrating information on functioning in National Health Information Systems. Am J Phys Med Rehabil. (2017) 96:677-81. doi: 10.1097/PHM.0000000000000688

24. Maritz R, Aronsky D, Prodinger B. The International Classification of Functioning, Disability and Health (ICF) in electronic health records. Appl Clin Inform. (2017) 8:964-80. doi: 10.4338/ACI2017050078

25. World Health Organization. Rehabilitation 2020. Available online at: https:// www.who.int/rehabilitation/rehab-2030/en/ (accessed 12 October, 2020).
26. Belova A, Fann N, Haskell J, Hubbell B, Narayan T. Estimating lifetime cost of illness: an application to asthma. Ann Am Thorac Soc. (2020) 17:1558-69. doi: 10.1513/AnnalsATS.201910-7 $290 \mathrm{C}$

27. Zhang X, Qiu H, Liu S, Li J, Zhou M. Prediction of prolonged length of stay for stroke patients on admission for inpatient rehabilitation based on the International Classification of Functioning, Disability, and Health (ICF) generic set: a study from 50 centers in China. Med Sci Monit. (2020) 26:e918811. doi: 10.12659/MSM.91 8811

28. United Nations. Convention on the Rights of Persons With Disabilities, G.A. Res. 61/106. (2007). Available online at: http://www.un.org/esa/socdev/enable/ rights/convtexte.htm (accessed 12 October, 2020).

29. Sengers JH, Abma FI, Wilming L, Roelofs PDDM, Heerkens YF, Brouwer SJ. Content validation of a practice-based work capacity assessment instrument using ICF core sets. J Occup Rehabil. (2020). doi: 10.1007/s10926-020-09918-7. [Epub ahead of print].

30. Momsen AH, Stapelfeldt CM, Rosbjerg R, Escorpizo R, Labriola M, Bjerrum M. International Classification of Functioning, Disability and Health in vocational rehabilitation: a scoping review of the state of the field. J Occup Rehabil. (2019) 29:241-73. doi: 10.1007/s10926-018-9788-4

31. Finger M, Escorpizo R, Bostan C, De Bie R. Work Rehabilitation Questionnaire (WOR Q): development and preliminary psychometric evidence of an ICF-based questionnaire for vocational rehabilitation. J Occup Rehabil. (2014) 24:498-510. doi: 10.1007/s10926-013-9485-2

32. Nützi M, Trezzini B, Staubli S, Ronca E, Schwegler U. An interdisciplinary approach to job matching: developing an occupation-specific job matching tool for reintegrating persons with spinal cord injury into the labor market. Disabil Rehabil. (2020) 42:2359-73. doi: 10.1080/09638288.2018.1561958

33. Heinemann AW, Miskovic A, Semik P, Wong A, Dashner J, Baum C, et al. Measuring environmental factors: unique and overlapping International Classification of Functioning, Disability and Health coverage of 5 instruments. Arch Phys Med Rehabil. (2016) 97:2113-22. doi: 10.1016/j.apmr.2016.05.021

34. Britto HMJS, Oliveira BS, Gomes CS, Pinto JM, Guerra RO. Contextual factors associated with life-space mobility in community-dwelling older adults based on International Classification of Functioning, Disability and Health: protocol for a systematic review. BMJ Open. (2018) 8:e023468. doi: 10.1136/bmjopen-2018-023468

35. Stucki G. Olle Höök Lectureship 2015: the World Health Organization's paradigm shift and implementation of the International Classification of Functioning, Disability and Health in rehabilitation. J Rehabil Med. (2016) 48:486-93. doi: 10.2340/16501977-2109

36. Oberhauser C, Chatterji S, Sabariego C, Cieza A. Development of a metric for tracking and comparing population health based on the minimal generic set of domains of functioning and health. Popul Health Metr. (2016) 14:19. doi: 10.1186/s12963-016-0088-y

37. Chatterji S, Byles J, Cutler D, Seeman T, Verdes, E. Health, functioning, and disability in older adults-present status and future implications. Lancet. (2015) 385:563-75. doi: 10.1016/S0140-6736(14)61462-

Conflict of Interest: The author declares that the research was conducted in the absence of any commercial or financial relationships that could be construed as a potential conflict of interest.

Copyright (c) 2021 Bickenbach. This is an open-access article distributed under the terms of the Creative Commons Attribution License (CC BY). The use, distribution or reproduction in other forums is permitted, provided the original author $(s)$ and the copyright owner(s) are credited and that the original publication in this journal is cited, in accordance with accepted academic practice. No use, distribution or reproduction is permitted which does not comply with these terms. 